Article

\title{
Sustainable Green Procedure for Extraction of Hesperidin from Selected Croatian Mandarin Peels
}

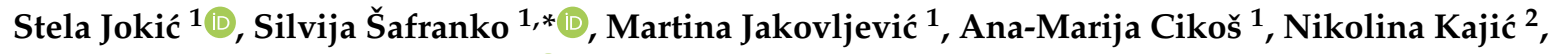 \\ Filip Kolarević ${ }^{1}$, Jurislav Babić ${ }^{1}\left[\right.$ and Maja Molnar ${ }^{1}$ \\ 1 Faculty of Food Technology Osijek, Josip Juraj Strossmayer University of Osijek, Franje Kuhača 20, \\ 31000 Osijek, Croatia \\ 2 Faculty of Agronomy and Food Technology, University of Mostar, Biskupa Čule bb, \\ 88000 Mostar, Bosnia and Herzegovina \\ * Correspondence: silvija.safranko@ptfos.hr; Tel.: +385-31-224-348
}

Received: 27 June 2019; Accepted: 18 July 2019; Published: 20 July 2019

\begin{abstract}
The peels of Citrus reticulata Blanco mandarin cultivars of different Croatian varieties (Zorica rana, Chahara, Okitsu, Kuno) were extracted using 15 different choline chloride-based deep eutectic solvents (DESs) at $50{ }^{\circ} \mathrm{C}$ for $30 \mathrm{~min}$ and with $20 \%$ water addition. The extracts were analyzed by high performance liquid chromatography with diode array detection (HPLC-DAD) to determine the most suitable DES for the extraction of hesperidin in the samples. The screening results indicated that choline chloride: acetamide (1:2) provided the most efficient hesperidin extraction $(112.14 \mathrm{mg} / \mathrm{g}$ of plant), while choline chloride:citric acid (1:1) solvent showed the lowest hesperidin yield (1.44 mg/g of plant). The Box-Behnken design was employed to optimize extraction parameters for each variety of mandarin peel, including extraction time, temperature and water content on hesperidin extraction. The results indicated that hesperidin content in mandarin peels was completely variety-dependent. Being a novel and efficient green media for hesperidin extraction, deep eutectic solvents could also serve as promising solvent systems for the production of extracts rich in bioactive compounds.
\end{abstract}

Keywords: by-product; deep eutectic solvents; hesperidin; mandarin peel; optimization

\section{Introduction}

Citrus fruits are one of the most important crops with worldwide production, while citrus by-products represent a problem regarding their disposal due to the environmental risk. Traditionally, the waste was either burned, causing an increase in carbon dioxide and other greenhouse gasses, or used for cattle feed, but today more environmentally friendly approach was developed for obtaining the new high-value products. The citrus by-products include pulp, seeds and peels, where seeds present a valuable by-product, as well as the peels, due to their content of natural antioxidants, primarily flavonoids [1]. The peels make the largest amount of total produced citrus by-products, and they can be utilized for different purposes due to their bioactive compounds content [2].

Composition of different constituents can vary regarding the diversity of citrus species and cultivars, as well as the genetic origin and the time of fruit collection. Therefore, citrus flavonoids can indicate the characteristic of each citrus species and variety [3]. Compounds found in mandarin peels, such as flavanone glycosides and polymethoxy flavones are recognized as the major contributors to the biological activity of peels [4], with hesperidin being the most abundant flavonoid and the main functional compound [5]. The studies have shown that it possesses hypoglycemic [6], antioxidant and cytotoxic effect against human cancer cell lines [7], anti-inflammatory [8] and antiproliferative activity [9]. Hesperidin also exerts growth-inhibitory effects in different cancers, as well as significant 
antimetastatic activity [10], while possessing many other beneficial effects, which were reviewed by Garg et al. [11].

Since different processes can be applied for the extraction of bioactive compounds from citrus fruit, it is very important to find the most efficient extraction method to obtain the highest yield of selected bioactive compounds. However, the content of biologically active compounds can vary, considering the applied method and operating conditions. Some of the extraction methods require the use of toxic and ecologically unacceptable organic solvents. Some authors $[12,13]$ investigated the extraction of hesperidin and other flavonoids from mandarin peels with isopropanol, ethanol and methanol, where ethanol is preferable for the application in the food processing due to the GRAS (generally recognized as dafe) characterization. Even though organic solvents can be applied for the extraction of specific compounds, their application in the food industry is unacceptable due to their toxicity and ecologically adverse effect. Therefore, more environmentally friendly solvents and methods should be applied. In the last few years, deep eutectic solvents (DESs) were proven a very efficient extraction media for obtaining different valuable compounds from various plant materials [14]. They are characterized as green, nontoxic and cheap solvents formed of hydrogen bond acceptors (HBAs) in combination with hydrogen bond donors (HBDs). In eutectic mixtures, HBAs are quaternary ammonium or metal salts, while HBDs can be amides, carboxylic acids, alcohols or sugars. When mixed in a certain ratio and depending on the type of used HBD and HBA, DESs with desirable properties are produced [15]. Recently, DESs are being used for the extraction of flavonoids from various fruits, vegetables and spices [16], as well as from Citrus aurantium L. [17] and the orange (Citrus sinensis) peels [18] where the DESs composition, concentration of added water, solid-to-liquid ratio and the effect of time, temperature and stirring speed on the extraction yield and composition of extracted flavonoids have been investigated. According to the results, DESs showed higher extraction yields and an increase in the solubility of active constituents compared to the other traditional solvents. The use of DESs as an extraction media has several advantages such as being environmentally friendly, with low cost and easy preparation of the solvents.

The work aimed to obtain the extracts rich in hesperidin from mandarin peels of Citrus reticulata Blanco cultivars of four selected Croatian variety including Zorica rana, Chahara, Okitsu and Kuno. Citrus reticulata Blanco is characterized by the greatest botanical variability [19]. The extraction was performed with 15 different DESs where HBA was choline chloride, while HBDs were compounds such as urea, acetamide, butane-1,4-diol, glycerol, citric acid, malic acid, sorbitol, xylitol, oxalic acid, levulinic acid, ethylene glycol, malonic acid, thiourea, N-methyl urea and lactic acid. First, the screening for the most suitable DES in the extraction of the highest amount of hesperidin was performed. Hesperidin content was determined by high performance liquid chromatography with diode array detection (HPLC-DAD) analysis, and the best solvent was found to be choline chloride: acetamide DES. Then, the optimal conditions for the extraction of hesperidin were determined using response surface methodology (RSM). The influence of the extraction temperature $\left(30,50\right.$ and $\left.70{ }^{\circ} \mathrm{C}\right)$, extraction time $(30,60$ and $90 \mathrm{~min}$ ) and the amount of added water $(10,20$ and $30 \%$ ) on the hesperidin content in the extracts obtained by choline chloride: acetamide DES was determined. This is the first report of the application of DESs for the extraction of hesperidin from four different Croatian variety of mandarin peels and the optimization of the process parameters.

\section{Materials and Methods}

\subsection{Chemicals and Plant Material}

The mandarin peels of Citrus reticulata Blanco cultivars of four different variety were obtained from small family farm Dalibor Ujević (Opuzen, Croatia) in 2017 during September (variety: Zorica rana), October (varieties: Chahara and Okitsu) and November (variety: Kuno). Before the extraction, the mandarin peels were dried and milled separately using a laboratory mill (IKA M 20 Universal mill). 
The hesperidin standard (purity 89.5\%) was obtained from Dr. Ehrenstorfer (Augsburg, Germany). All solvents were of analytical grade and purchased from J.T. Baker (J.T. Baker, Phillipsburg, NJ, USA).

\subsection{Preparation of Deep Eutectic Solvents (DESs)}

DESs were prepared by mixing choline chloride $(\mathrm{ChCl})$ as $\mathrm{HBA}$ with 15 different HBDs (urea, acetamide, butane-1,4-diol, glycerol, citric acid, malic acid, sorbitol, xylitol, oxalic acid, levulinic acid, ethylene glycol, malonic acid, thiourea, $\mathrm{N}$-methyl urea, lactic acid) in certain molar ratio as specified in Table 1. A mixture was heated to $80^{\circ} \mathrm{C}$ under constant stirring until a stable homogeneous liquid was formed.

Table 1. List of DESs prepared and tested for the extraction of hesperidin from mandarin peels.

\begin{tabular}{|c|c|c|c|}
\hline \multirow[b]{2}{*}{ Abbreviation } & \multicolumn{2}{|c|}{ Components } & \multirow[b]{2}{*}{ Mole Ratio (HBA: HBD) } \\
\hline & $\begin{array}{l}\text { Hydrogen Bond Acceptors } \\
\text { (HBAs) }\end{array}$ & $\begin{array}{l}\text { Hydrogen Bond Donors } \\
\text { (HBDs) }\end{array}$ & \\
\hline $\mathrm{ChCl}-\mathrm{AA}$ & Choline chloride & Acetamide & $1: 2$ \\
\hline ChCl-BDO & & Butane-1,4-diol & $1: 2$ \\
\hline $\mathrm{ChCl}-\mathrm{CiA}$ & & Citric acid & $1: 1$ \\
\hline ChCl-EG & & Ethylene glycol & $1: 1$ \\
\hline $\mathrm{ChCl}-\mathrm{GL}$ & & Glycerol & $1: 2$ \\
\hline $\mathrm{ChCl}-\mathrm{Lac}$ & & Lactic acid & $1: 1$ \\
\hline ChCl-LeA & & Levulinic acid & $1: 1$ \\
\hline ChCl-MAc & & Malonic acid & $1: 1$ \\
\hline ChCl-Mal & & Malic acid & $1: 1$ \\
\hline ChCl-NMeU & & N-methyl urea & $1: 3$ \\
\hline ChCl-OxA & & Oxalic acid & $1: 1$ \\
\hline ChCl-Sor & & Sorbitol & $1: 1$ \\
\hline ChCl-ThU & & Thiourea & $1: 1$ \\
\hline $\mathrm{ChCl-U}$ & & Urea & $1: 1$ \\
\hline ChCl-Xyl & & Xylitol & $1: 1$ \\
\hline
\end{tabular}

\subsection{Extraction of Hesperidin from Mandarin Peels with DESs}

Dried and milled mandarin peels of each variety (Zorica rana, Chahara, Okitsu, Kuno) (50 mg) were mixed with $1 \mathrm{~mL}$ of the solvent, i.e., a mixture of DES with $20 \%(v / v)$ of demineralized water for screening. For initial screening, the mixture of DES and $20 \%$ of added water $(v / v)$ was stirred at a temperature of $50{ }^{\circ} \mathrm{C}$ for $30 \mathrm{~min}$. After optimization of the extraction process was performed, DESs were mixed with different amount of water $(v / v)$ as emphasized in Table 2, at specified temperature and time. In both cases, prepared samples were stirred at $1500 \mathrm{rpm}$ in aluminum block on a magnetic stirrer. After the extraction, the mixture was centrifuged at $6000 \mathrm{rpm}$ for $5 \mathrm{~min}$ and then decanted. The supernatant $(200 \mu \mathrm{L})$ was then diluted with $800 \mu \mathrm{L}$ of methanol and filtered through the PTFE $0.45 \mu \mathrm{m}$ filter before HPLC analysis. 
Table 2. Coded and actual levels of the independent variable for the Box-Behnken design with experimental hesperidin yields.

\begin{tabular}{|c|c|c|c|c|c|c|c|}
\hline \multirow{2}{*}{\multicolumn{2}{|c|}{ Independent Variable }} & \multirow{2}{*}{\multicolumn{2}{|c|}{ Symbol }} & \multicolumn{4}{|c|}{ Level } \\
\hline & & & & Low $(-1)$ & \multicolumn{2}{|c|}{ Middle (0) } & High $(+1)$ \\
\hline \multicolumn{2}{|c|}{ Time (min) } & \multicolumn{2}{|c|}{$X_{1}$} & 30 & \multicolumn{2}{|c|}{60} & 90 \\
\hline \multicolumn{2}{|c|}{ Temperature $\left({ }^{\circ} \mathrm{C}\right)$} & \multicolumn{2}{|c|}{$X_{2}$} & 30 & \multicolumn{2}{|c|}{50} & 70 \\
\hline \multicolumn{2}{|c|}{ Water content $(\%)$} & \multicolumn{2}{|c|}{$X_{3}$} & 10 & \multicolumn{2}{|c|}{20} & 30 \\
\hline & & & & Okitsu & Chahara & Kuno & $\begin{array}{c}\text { Zorica } \\
\text { Rana }\end{array}$ \\
\hline Run & $X_{1}$ & $X_{2}$ & $X_{3}$ & \multicolumn{4}{|c|}{ Hesperidin (mg/g of plant) } \\
\hline 1 & 90 & 30 & 20 & 40.45 & 103.17 & 132.35 & 156.47 \\
\hline 2 & 30 & 30 & 20 & 124.01 & 92.35 & 91.03 & 98.12 \\
\hline 3 & 30 & 50 & 30 & 110.03 & 88.36 & 137.66 & 123.48 \\
\hline 4 & 90 & 50 & 30 & 88.89 & 68.41 & 120.14 & 81.99 \\
\hline 5 & 60 & 50 & 20 & 195.32 & 110.15 & 189.84 & 179.96 \\
\hline 6 & 60 & 50 & 20 & 169.81 & 105.70 & 144.08 & 194.50 \\
\hline 7 & 60 & 70 & 30 & 104.39 & 90.40 & 136.88 & 123.59 \\
\hline 8 & 60 & 50 & 20 & 155.82 & 107.45 & 172.13 & 177.85 \\
\hline 9 & 60 & 50 & 20 & 183.55 & 116.02 & 152.80 & 167.06 \\
\hline 10 & 60 & 30 & 10 & 53.83 & 97.27 & 59.33 & 124.05 \\
\hline 11 & 30 & 50 & 10 & 139.29 & 126.11 & 112.67 & 136.91 \\
\hline 12 & 60 & 70 & 10 & 140.94 & 136.86 & 95.45 & 204.05 \\
\hline 13 & 60 & 30 & 30 & 91.46 & 95.76 & 109.34 & 85.46 \\
\hline 14 & 60 & 50 & 20 & 147.15 & 98.43 & 142.74 & 134.05 \\
\hline 15 & 90 & 70 & 20 & 171.56 & 109.91 & 168.11 & 207.88 \\
\hline 16 & 90 & 50 & 10 & 167.48 & 124.03 & 167.89 & 192.86 \\
\hline 17 & 30 & 70 & 20 & 154.67 & 111.06 & 170.67 & 188.36 \\
\hline
\end{tabular}

\subsection{HPLC Analysis of Hesperidin in the Extracts}

Hesperidin was determined using a RP-HPLC method described in paper by Sun et al. [20] on a Agilent 1260 Infinity II (Analytical Instruments, CA, USA) with chromatographic separation obtained on a ZORBAX Eclipse Plus C18 (Agilent, CA, USA) column $(100 \times 4.6 \mathrm{~mm}, 5 \mu \mathrm{m})$ with isocratic elution of water as phase $\mathrm{A}$ and acetonitrile as phase $\mathrm{B}$, at room temperature during $10 \mathrm{~min}$. The flow rate was $1.0 \mathrm{~mL} / \mathrm{min}$, an injection volume of $20 \mu \mathrm{L}$ was used, and UV detection wavelength was $210 \mathrm{~nm}$. Hesperidin standard stock solutions were prepared in the methanol and calibration was obtained at seven concentrations $(20.0-200.0 \mathrm{mg} / \mathrm{L})$. The linearity of the hesperidin calibration curve was confirmed by $R^{2}=0.99955$ with the limit of detection (LOD) of $0.001062 \mathrm{mg} / \mathrm{L}$, quantification limit (LOQ) of $0.00354 \mathrm{mg} / \mathrm{L}$ and hesperidin retention time was $4.153 \mathrm{~min}$. Results for obtained hesperidin content are given in Table 2.

\subsection{Experimental Design}

In order to evaluate the influence of three independent variables on hesperidin content in mandarin peel response, surface methodology technique (RSM) was applied. The process was analyzed and optimized with a Box-Behnken Design model in a quadratic function consisting of 17 randomized experimental runs with included five replicates at the central point. The effects of extraction time (30-90 $\left.\mathrm{min} ; X_{1}\right)$, temperature $\left(30-70{ }^{\circ} \mathrm{C} ; X_{2}\right)$ and water content $\left(10-30 \% ; X_{3}\right)$ was investigated on the hesperidin yield $(y)$ obtained by DES extraction. The coded and actual values of the independent variables used in experimental design are shown in Table 2. Statistical analysis and design of experiments were performed using Design-Expert ${ }^{\circledR}$ software (ver. 9, Stat-Ease Inc., Minneapolis, MN, USA) to determine the optimal extraction conditions for maximizing hesperidin content in the mandarin peel. 


\subsection{Development of the RSM Model}

A second-order polynomial model is developed based on three input variables for hesperidin content in mandarin peel prediction and extraction process optimization: Time $\left(X_{1}\right)$, temperature $\left(X_{2}\right)$ and water content $\left(X_{3}\right)$. Coded and actual levels of the independent process variables for RSM experimental design are shown in Table 2. A quadratic model for this study can be expressed by Equation (1):

$$
y=\beta_{0}+\sum_{i=1}^{k} \beta_{i} X_{i}+\sum_{i=1}^{k} \beta_{i i} X_{i}^{2}+\sum_{\substack{i=1 \\ i<j}}^{k-1} \sum_{j=2}^{k} \beta_{i j} X_{i} X_{j},
$$

where $y$ is the response or dependent variable, $\beta_{0}$ is the constant variable representing intercept, $\beta_{i}, \beta_{i i}$ and $\beta_{i j}$ designate regression coefficients, $X_{i}$ and $X_{j}$ are inputs or independent variables. A relationship between individual factors $X_{i}$ is described with linear coefficients $\beta_{i}$, cross product $X_{i j}$ with interaction coefficients $\beta_{i j}$ and quadratic variable $X_{i i}$ with quadratic coefficients $\beta_{i i}$ respectively. The RSM uses the least square method to estimate regression coefficients, which are used in model fitting. The adequacy of the fitted models is tested and evaluated through Lack of Fit, F-value and $p$-value of the ANOVA.

\section{Results and Discussion}

\subsection{Screening of DES for Hesperidin Extraction}

Since DESs are synthesized with various HBDs, they have a different physical, and chemical properties, like viscosity, $\mathrm{pH}$, surface tension and polarity, and all of these parameters can have a significant influence on the extraction of hesperidin. Hence, in order to determine which DES is the most effective in the extraction of hesperidin, the extraction at constant process parameters was performed with 15 different DESs (Table 1).

The chosen extraction parameters were $50{ }^{\circ} \mathrm{C}, 20 \% \mathrm{H}_{2} \mathrm{O}$ content and $30 \mathrm{~min}$. The extraction time of 30 minutes and extraction temperature was chosen according to our own experience, as well as according to Liu et al. [17] who have shown that $30 \mathrm{~min}$ was the optimal time to extract hesperidin. Water content is important for reducing viscosity, but very high water content reduces the interaction between components, therefore, $20 \%(v / v)$ of water was selected.

Typical HPLC-DAD chromatogram and UV spectrum of hesperidin standard are shown in Figure 1a, as well as exemplary HPLC chromatogram of hesperidin quantification and separation from mandarin peels (Figure 1b).

a)

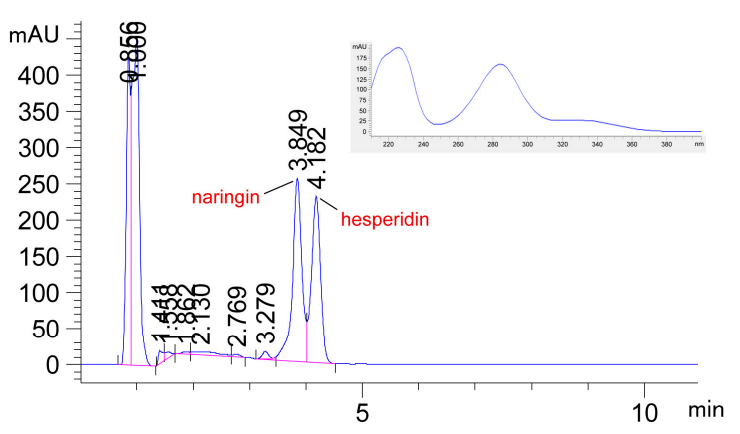

b)

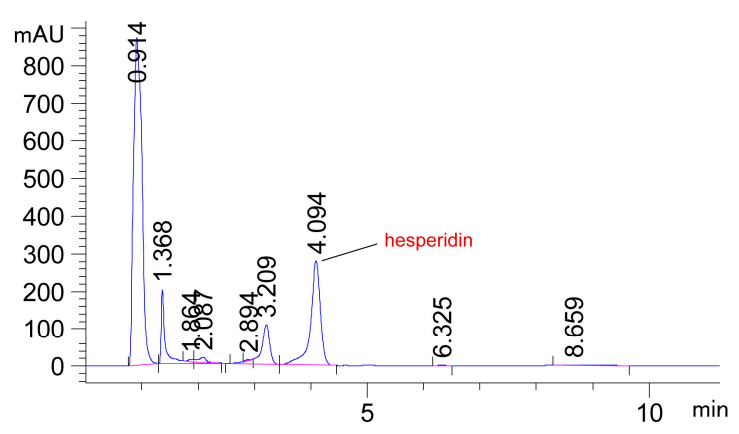

Figure 1. High performance liquid chromatography (HPLC)-DAD chromatograms for hesperidin analysis: (a) HPLC chromatogram of naringin and hesperidin standards (inset: UV spectrum of hesperidin standard); (b) HPLC chromatogram of hesperidin in mandarin peel sample.

As can be seen from Figure 2, there is a significant difference in the extraction ability among the used solvents at constant parameters, as well as between mandarin varieties. The highest amount 
of hesperidin was extracted with ChCl-AA $(102.0,68.3,88.7,112.1 \mathrm{mg} / \mathrm{g}$ of plant for Okitsu, Chahara, Kuno and Zorica rana respectively), while the lowest amount was extracted with ChCl-CiA (3.3, 1.4, $9.8,4.2 \mathrm{mg} / \mathrm{g}$ of plant for Okitsu, Chahara, Kuno and Zorica rana), possibly due to increased viscosity of the solvent itself. Generally, the highest hesperidin content was extracted using basic DESs, such as $\mathrm{ChCl}-\mathrm{AA}, \mathrm{ChCl}-\mathrm{U}$ and $\mathrm{ChCl}-\mathrm{NMeU}$. Similar results have been achieved with DESs such as ChCl-EG and $\mathrm{ChCl}-\mathrm{BDO}$, while between acid eutectic solvents most efficacious in the extraction of hesperidin were ChCl-LeA and ChCl-Mac, although basic DESs exhibit much higher yield (38.8-102.0, 26.8-68.7, 7.3-8.87, 17.6-112.1 mg/g of plant for Okitsu, Chahara, Kuno and Zorica rana) than other DESs for the extraction of desired component (Figure 2).

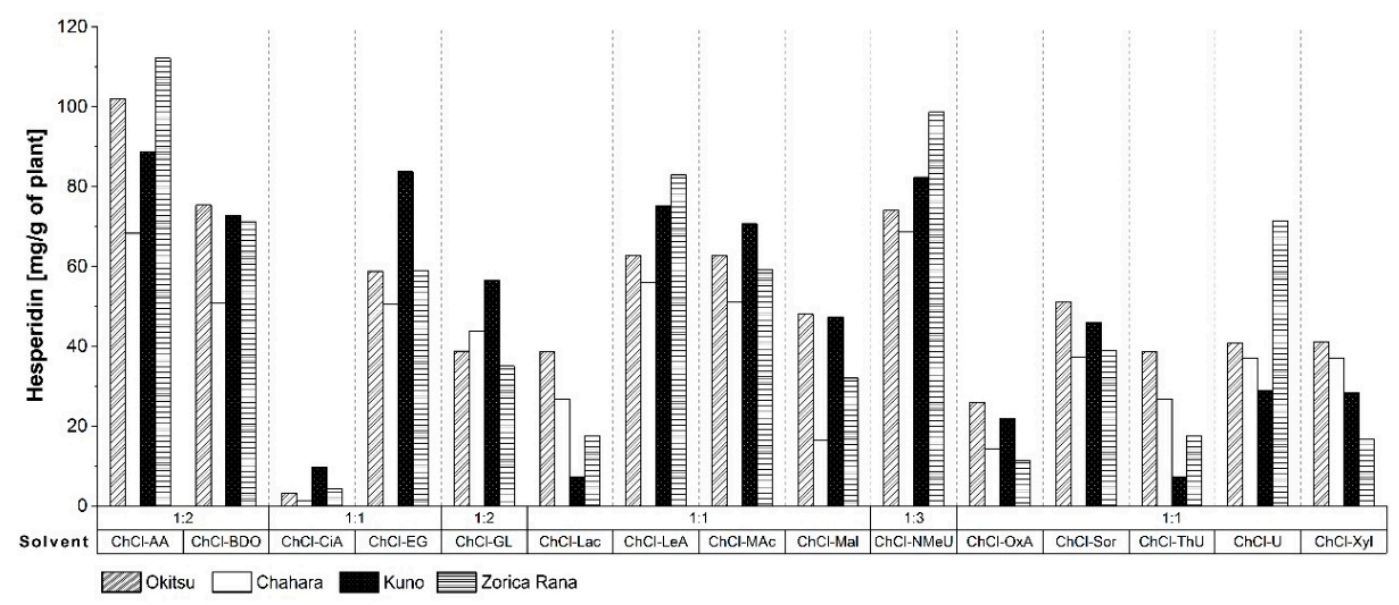

Figure 2. Comparative study of obtained hesperidin yields using different combinations of deep-eutectic solvents (DESs) comprising choline chloride ( $\mathrm{ChCl}$ ) and acetamide (AA), butane-1,4-diol (BDO), citric acid (CiA), ethylene glycol (EG), glycerol (GL), lactic acid (Lac), levulinic acid (LeA), malonic acid (Mac), malic acid (Mal), N-methyl urea (NmeU), oxalic acid (OxA), sorbitol (Sor), thiourea (ThU), urea (U), and xylitol (Xyl).

According to Budavari [21], hesperidin is soluble in dilute alkali and pyridine which is also proven in the paper by Al-Ashaal et al. [7], where extraction with alkaline solution gave the highest hesperidin yield. Given the higher extraction efficiency of solvent ChCl-AA compared to other basic solvents, the following was selected for further investigation and optimization.

\subsection{Response Surface Analysis and Process Optimization}

In order to optimize the extraction process, it is essential to evaluate the effects of several process variables (time, temperature and water content) and their interactions on the response (hesperidin content). Summarized results of the ANOVA are shown in Table 3 in order to evaluate the statistical significance of the proposed models for each investigated response. In this research, the investigated response is the extracted hesperidin content from the mandarin peel of different varieties. 
Table 3. Analysis of variance (ANOVA) of second-order polynomial models for hesperidin content in the mandarin peels.

\begin{tabular}{|c|c|c|c|c|c|}
\hline Source & Sum of Squares & Degree of Freedom & Mean Square & F Value & $p$-Value ${ }^{\mathrm{a}}$ \\
\hline \multicolumn{6}{|l|}{ Okitsu } \\
\hline Model & 27478.88 & 9 & 3053.21 & 5.11 & 0.0215 * \\
\hline Residual & 4186.19 & 7 & 598.03 & & \\
\hline Lack of fit & 2638.68 & 3 & 879.56 & 2.27 & 0.2221 \\
\hline Pure error & 1547.52 & 4 & 386.88 & & \\
\hline Total & 31665.07 & 16 & & & \\
\hline \multicolumn{6}{|l|}{$R^{2}=0.8678$} \\
\hline \multicolumn{6}{|l|}{ Chahara } \\
\hline Model & 3659.79 & 9 & 406.64 & 5.10 & 0.0215 * \\
\hline Residual & 557.94 & 7 & 79.71 & & \\
\hline Lack of fit & 392.92 & 3 & 130.97 & 3.17 & 0.1468 \\
\hline Pure error & 165.02 & 4 & 41.25 & & \\
\hline Total & 4217.73 & 16 & & & \\
\hline \multicolumn{6}{|l|}{$R^{2}=0.8677$} \\
\hline \multicolumn{6}{|l|}{ Kuno } \\
\hline Model & 13543.90 & 9 & 1504.88 & 4.17 & 0.0364 * \\
\hline Residual & 2523.63 & 7 & 360.52 & & \\
\hline Lack of fit & 1965.27 & 3 & 655.09 & 4.69 & 0.0847 \\
\hline Pure error & 558.36 & 4 & 139.59 & & \\
\hline Total & 16067.53 & 16 & & & \\
\hline \multicolumn{6}{|l|}{$R^{2}=0.8429$} \\
\hline \multicolumn{6}{|l|}{ Zorica rana } \\
\hline Model & 24872.12 & 9 & 2763.57 & 7.34 & $0.0077^{* *}$ \\
\hline Residual & 2635.01 & 7 & 376.43 & & \\
\hline Lack of fit & 575.09 & 3 & 191.70 & 0.3722 & 0.7785 \\
\hline Pure error & 2059.92 & 4 & 514.98 & & \\
\hline Total & 27507.13 & 16 & & & \\
\hline$R^{2}=0.9042$ & & & & & \\
\hline
\end{tabular}

Based on the obtained results, the regression models for all investigated responses of Citrus reticulata varieties were significant $(p$-value $<0.05)$, while the quality of the models developed was evaluated based on the coefficients of determination $\left(R^{2}\right)$ and Lack of fit value. The obtained $R^{2}$ values for all models developed was in the range from 0.8429 to 0.9042 with non-significant Lack of fit indicated adequate representation between input parameters and observed variable, in this case, hesperidin content in mandarin peel of different varieties. The model developed for the variety Okitsu implies no significant influence of the extraction time or water content on the process of hesperidin extraction using DESs.

However, temperature and quadratic terms of temperature and water content variables showed significant influence on the extraction process as given in Table 4. 
Table 4. Estimated coefficients of the regression model for hesperidin content.

\begin{tabular}{|c|c|c|c|c|}
\hline Source & Coefficients & Standard Error & F-Value & $p$-Value ${ }^{\text {a }}$ \\
\hline \multicolumn{5}{|l|}{ Okitsu } \\
\hline \multicolumn{5}{|l|}{ Intercept } \\
\hline$\beta_{0}$ & 170.33 & 10.94 & & \\
\hline \multicolumn{5}{|l|}{ Linear } \\
\hline$\beta_{1}$ & -7.45 & 8.65 & 0.74 & 0.4173 \\
\hline$\beta_{2}$ & 32.73 & 8.65 & 14.33 & $0.0068^{* *}$ \\
\hline$\beta_{3}$ & -13.35 & 8.65 & 2.38 & 0.1666 \\
\hline \multicolumn{5}{|c|}{ Cross product } \\
\hline$\beta_{12}$ & 25.11 & 12.23 & 4.22 & 0.0791 \\
\hline$\beta_{13}$ & -12.33 & 12.23 & 1.02 & 0.3468 \\
\hline$\beta_{23}$ & -18.55 & 12.23 & 2.30 & 0.1731 \\
\hline \multicolumn{5}{|c|}{ Quadratic } \\
\hline$\beta_{11}$ & -9.44 & 11.92 & 0.63 & 0.4541 \\
\hline$\beta_{22}$ & -38.21 & 11.92 & 10.28 & 0.0149 * \\
\hline$\beta_{33}$ & -34.46 & 11.92 & 8.36 & 0.0233 * \\
\hline C.V. \% & 18.57 & & & \\
\hline \multicolumn{5}{|l|}{ Chahara } \\
\hline \multicolumn{5}{|l|}{ Intercept } \\
\hline$\beta_{0}$ & 107.55 & 3.99 & & \\
\hline \multicolumn{5}{|l|}{ Linear } \\
\hline$\beta_{1}$ & -1.54 & 3.16 & 0.24 & 0.6396 \\
\hline$\beta_{2}$ & 7.46 & 3.16 & 5.58 & 0.0501 \\
\hline$\beta_{3}$ & -17.67 & 3.16 & 31.33 & $0.0008^{* *}$ \\
\hline \multicolumn{5}{|c|}{ Cross product } \\
\hline$\beta_{12}$ & -2.99 & 4.46 & 0.45 & 0.5241 \\
\hline$\beta_{13}$ & -4.47 & 4.46 & 1.00 & 0.3505 \\
\hline$\beta_{23}$ & -11.24 & 4.46 & 6.34 & 0.0399 * \\
\hline \multicolumn{5}{|c|}{ Quadratic } \\
\hline$\beta_{11}$ & -3.39 & 4.35 & 0.61 & 0.4619 \\
\hline$\beta_{22}$ & -0.0400 & 4.35 & 0.0001 & 0.9929 \\
\hline$\beta_{33}$ & -2.44 & 4.35 & 0.31 & 0.5929 \\
\hline C.V. $\%$ & 8.52 & & & \\
\hline \multicolumn{5}{|l|}{ Kuno } \\
\hline \multicolumn{5}{|l|}{ Intercept } \\
\hline$\beta_{0}$ & 152.32 & 8.49 & & \\
\hline \multicolumn{5}{|l|}{ Linear } \\
\hline$\beta_{1}$ & 9.56 & 6.71 & 2.03 & 0.1976 \\
\hline$\beta_{2}$ & 22.38 & 6.71 & 11.12 & 0.0125 * \\
\hline$\beta_{3}$ & 8.58 & 6.71 & 1.64 & 0.2417 \\
\hline \multicolumn{5}{|c|}{ Cross product } \\
\hline$\beta_{12}$ & -10.97 & 9.49 & 1.34 & 0.2858 \\
\hline$\beta_{13}$ & -18.18 & 9.49 & 3.67 & 0.0970 \\
\hline$\beta_{23}$ & -2.14 & 9.49 & 0.0509 & 0.8279 \\
\hline \multicolumn{5}{|c|}{ Quadratic } \\
\hline$\beta_{11}$ & 11.28 & 9.25 & 1.49 & 0.2623 \\
\hline$\beta_{22}$ & -23.06 & 9.25 & 6.21 & 0.0415 * \\
\hline$\beta_{33}$ & -29.01 & 9.25 & 9.83 & 0.0165 * \\
\hline C.V. $\%$ & 14.26 & & & \\
\hline
\end{tabular}


Table 4. Cont.

\begin{tabular}{|c|c|c|c|c|}
\hline Source & Coefficients & Standard Error & F-Value & $p$-Value ${ }^{\text {a }}$ \\
\hline \multicolumn{5}{|c|}{ Zorica rana } \\
\hline $\begin{array}{c}\beta_{0} \\
\text { Linear }\end{array}$ & Linear & 8.68 & & \\
\hline$\beta_{1}$ & 11.54 & 6.86 & 2.83 & 0.1364 \\
\hline$\beta_{2}$ & 32.47 & 6.86 & 22.41 & $0.0021^{* *}$ \\
\hline$\beta_{3}$ & -30.42 & 6.86 & 19.66 & $0.0030 * *$ \\
\hline \multicolumn{5}{|c|}{ Cross product } \\
\hline$\beta_{12}$ & -9.71 & 9.70 & 1.00 & 0.3503 \\
\hline$\beta_{13}$ & -24.36 & 9.70 & 6.31 & 0.0403 * \\
\hline$\beta_{23}$ & -10.47 & 9.70 & 1.16 & 0.3163 \\
\hline \multicolumn{5}{|c|}{ Quadratic } \\
\hline$\beta_{11}$ & -4.23 & 9.46 & 0.2 & 0.6682 \\
\hline$\beta_{22}$ & -3.75 & 9.46 & 0.16 & 0.7034 \\
\hline$\beta_{33}$ & -32.65 & 9.46 & 11.92 & 0.0106 * \\
\hline C.V. $\%$ & 12.80 & & & \\
\hline
\end{tabular}

In addition, the temperature was a significant parameter for all models except for the model developed for Citrus reticulata variety Chahara, showing increased hesperidin yield with the increase of the temperature. An interesting observation has been made about the influence of the water content for varieties of Chahara and Zorica rana where water content parameter showed a significant effect on the hesperidin yield from mandarin peels (Figure $3 b, c$ ).

As can be seen, the increase in water content causes the increase in hesperidin yield until it reaches its maximum (mostly around 20\%). After that, the additional increase in water content (above $20 \%$ ) causes the hesperidin yield to decrease. This phenomenon could be potentially explained by the fact that higher water content weakens the interactions between DESs and hesperidin.

Water content is important, since it reduces the viscosity of the solvent, thereby improving the mass transfer and extraction process. However, the excessive water content can reduce the interaction between the solvent components, as well as the solvent and the desired component interactions [22]. Addition of water up to $20 \%$ reduces the viscosity of the solvent contributing to the better extraction, and with further increase in the water content above $20 \%$ the needed interactions are reduced, as well as the extracted content of hesperidin. Since hesperidin is a component that is very poorly soluble in water, it is understandable that the increase in water addition decreases its solubility in the solvent [23]. One of the main goals of this study is to optimize DES extraction processes by maximizing hesperidin yield using desirability approach.

For the variety Okitsu, the optimal conditions for hesperidin extraction were estimated to be at time $90 \mathrm{~min}$, at a temperature of $68.14{ }^{\circ} \mathrm{C}$, and water content of $13.83 \%$. Moreover, optimal conditions were calculated to be at $45.40 \mathrm{~min}, 69.70{ }^{\circ} \mathrm{C}$ and water content of $10.67 \%$ for variety of Chahara, while 88.79 and $54.72 \mathrm{~min}, 55.02$ and $69.66^{\circ} \mathrm{C}, 19.73$ and $14.86 \%$ were calculated as optimal conditions for hesperidin extraction by DES of choline chloride and acetamide in 1:2 molar ratio for Kuno and Zorica rana, respectively. Predicted data obtained with RSM analysis for each investigated variety were experimentally verified with a good agreement to the experimental values within a deviation of $\pm 5 \%$. Moreover, in order to evaluate the obtained models, a graphical comparison was made of the actual versus predicted values for responses of the four different mandarin varieties, as shown in Figure 4. 

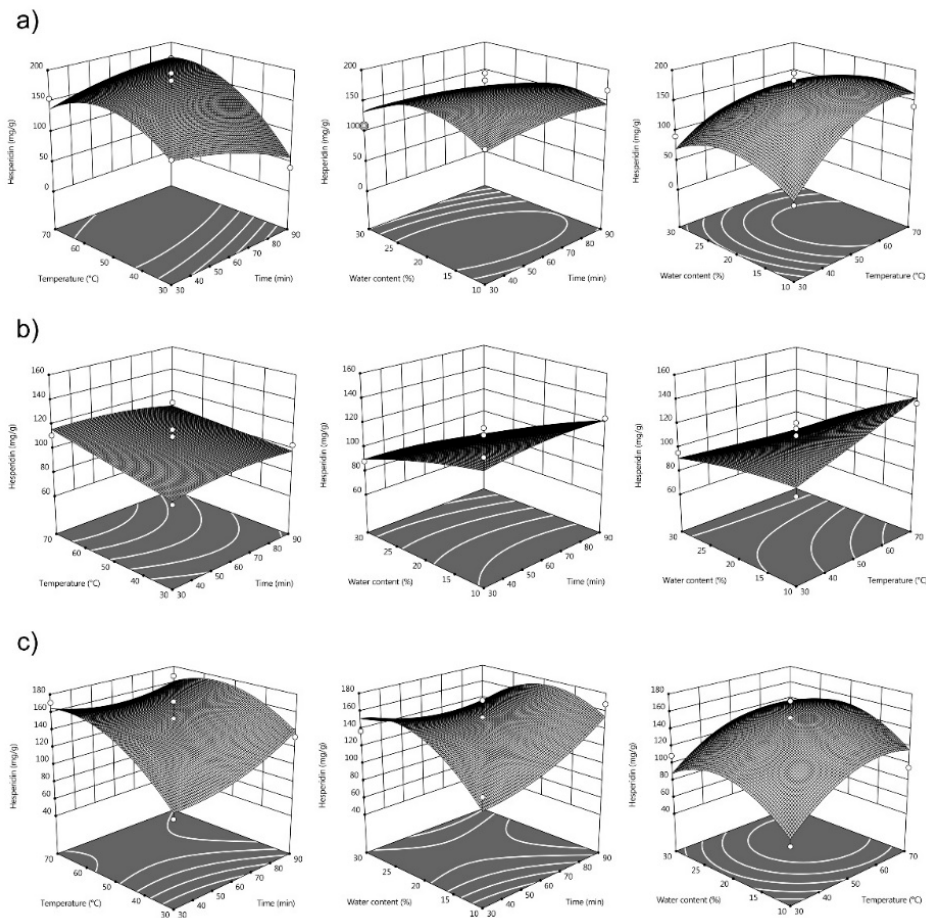

d)
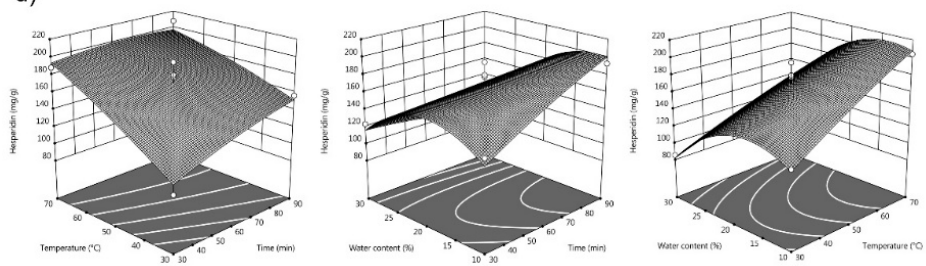

Figure 3. Response surface plots showing the effects of temperature, extraction time and water content on the extraction yield of hesperidin in different mandarin varieties: (a) Okitsu; (b) Chahara; (c) Kuno; (d) Zorica Rana.
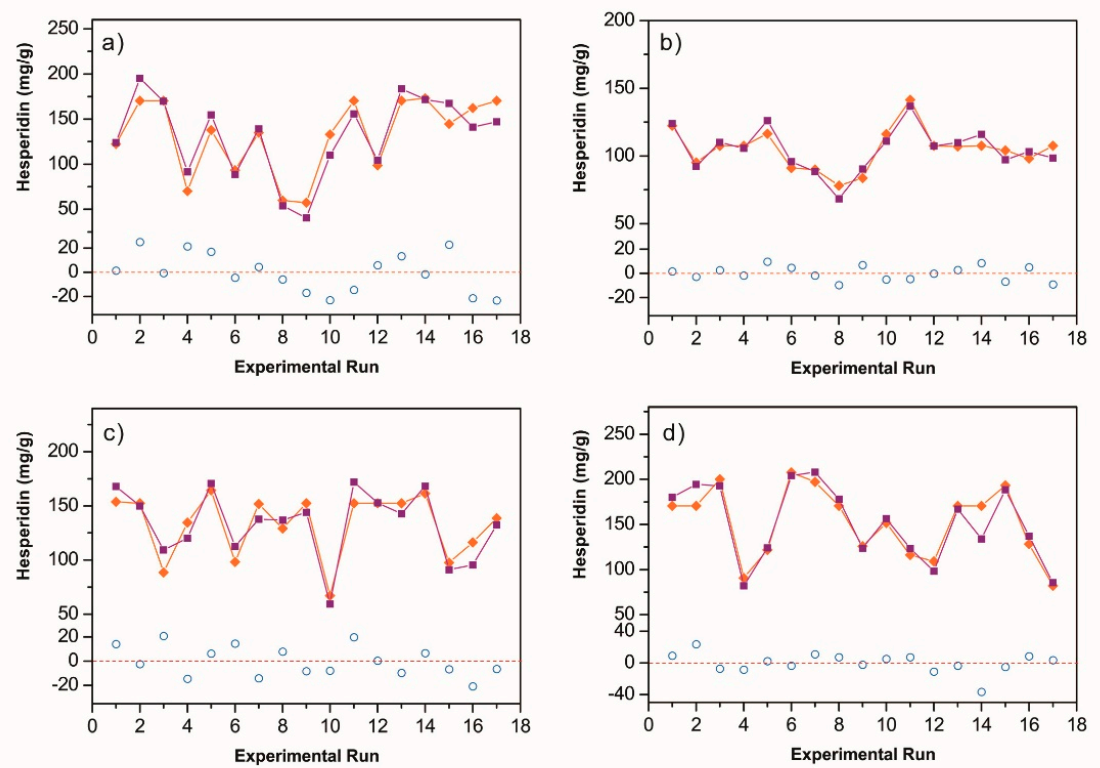

$-\square-$ Actual Value $\longrightarrow$ - Predicted Value $\bigcirc$ Residuals

Figure 4. Graphical comparison of actual and predicted values of the extracted hesperidin content for each variety of mandarin: (a) Okitsu; (b) Chahara; (c) Kuno; (d) Zorica Rana. 
A literature search did not reveale data on DESs extraction and optimization of the parameters for hesperidin from Citrus reticulata, but there few papers that investigate the possibility of extraction using other solvents. Given the different varieties, as well as the geographical position and time of harvest, it is difficult to make an adequate comparison of our results.

Tumbas et al. [5] extracted hesperidin from mandarin (Citrus reticulata) peel with $70 \%(v / v)$ aqueous solution of acetone during $2 \mathrm{~h}$ at a temperature of $40^{\circ} \mathrm{C}$ at magnetic stirrer. The quantitative analysis showed that the obtained hesperidin content from mandarin peel was $31.42 \mathrm{mg} / \mathrm{g}$ of plant. In the case of kinnow peels, hesperidin was extracted with methanol and ethanol $(50,80,100 \%)$ respectively. The obtained contents of hesperidin extracted with methanol were in the range from $44.38 \pm 1.08$ to $61.02 \pm 1.17 \mu \mathrm{g} / \mathrm{g}$ of extract and with ethanol $75.66 \pm 1.67-92.94 \pm 1.23 \mu \mathrm{g} / \mathrm{g}$ of the extract [13].

\section{Conclusions}

In this study, the results of a systematic and comparative study of hesperidin extraction using DESs from the mandarin peel of different varieties are presented. Fifteen different deep eutectic choline chloride-based solvents have been used to extract hesperidin, a bioflavonoid possessing many biological activities. The screening results demonstrated the highest extraction efficiency obtained with choline chloride: acetamide solvent, which has been used in further study, while choline chloride:citric acid solvent showed the lowest efficiency of hesperidin extraction. Our findings also indicate the significant impact of mandarin assortment on obtained hesperidin content in extracts, as the highest content of hesperidin was found in variety Zorica rana, followed by the content found in variety Okitsu. The Box-Behnken design was employed to determine the optimal extraction conditions for each variety of mandarin peel, and the RSM analysis showed that influences of different operating parameters are variety-dependent.

To our knowledge, this is the first systematic study on hesperidin extraction and process optimization from mandarin peel and there are no previous studies comparing the efficiency of different DES on the extraction of the mandarin peel of different varieties. All these findings could be useful for obtaining highly valuable bioactive compounds by novel extraction methods, as well for minimizing the considerable issue of waste disposal. Furthermore, the presence of unidentified compounds in HPLC spectrum offers strong support for future studies of investigation and separation of bioactive compounds (e.g., flavonoids) present in citrus peel.

Author Contributions: S.J. designed the experiments; S.Š. data analysis; M.J. performed HPLC analysis; A.-M.C. and F.K. performed the extraction experiments; N.K. provided plant material; J.B. funding acquisition; M.M. supervision and methodology. All the authors were included in Writing-Review and Editing the manuscript and approved the final version of the paper.

Funding: This research was funded by Croatian Science Foundation under the project UIP-2017-05-9909.

Acknowledgments: This work has been supported by Croatian Science Foundation under the project "Application of innovative techniques of the extraction of bioactive compounds from by-products of plant origin" (UIP-2017-05-9909).

Conflicts of Interest: The authors declare no conflict of interest.

\section{References}

1. Moulehi, I.; Bourgou, S.; Ourghemmi, I.; Saidani Tounsi, M. Variety and ripening impact on phenolic composition and antioxidant activity of mandarin (Citrus reticulate Blanco) and bitter orange (Citrus aurantium L.) seeds extracts. Ind. Crops Prod. 2012, 39, 74-80. [CrossRef]

2. Mamma, D.; Christakopoulos, P. Biotransformation of Citrus By-Products into Value Added Products. Waste Biomass Valorization 2014, 5, 529-549. [CrossRef]

3. Lu, Y.; Zhang, C.; Bucheli, P.; Wei, D. Citrus Flavonoids in Fruit and Traditional Chinese Medicinal Food Ingredients in China. Plant Foods Hum. Nutr. 2006, 61, 57-65. [CrossRef] [PubMed]

4. Huang, Y.S.; Ho, S.C. Polymethoxy flavones are responsible for the anti-inflammatory activity of citrus fruit peel. Food Chem. 2010, 119, 868-873. [CrossRef] 
5. Tumbas, V.T.; Ćetković, G.S.; Djilas, S.M.; Čanadanović-Brunet, J.M.; Vulić, J.J.; Knez, Ž.; Škerget, M. Antioxidant activity of mandarin (Citrus reticulata) peel. Acta Period. Technol. 2010, 41, 195-203. [CrossRef]

6. Jung, U.J.; Lee, M.K.; Jeong, K.S.; Choi, M.S. The Hypoglycemic Effects of Hesperidin and Naringin Are Partly Mediated by Hepatic Glucose-Regulating Enzymes in C57BL/KsJ-db/db Mice. J. Nutr. 2004, 134, 2499-2503. [CrossRef]

7. Al-Ashaal, H.A.; El-Sheltawy, S.T. Antioxidant capacity of hesperidin from Citrus peel using electron spin resonance and cytotoxic activity against human carcinoma cell lines. Pharm. Biol. 2011, 49, $276-282$. [CrossRef] [PubMed]

8. Guardia, T.; Rotelli, A.E.; Juarez, A.O.; Pelzer, L.E. Anti-inflammatory properties of plant flavonoids. Effects of rutin, quercetin and hesperidin on adjuvant arthritis in rat. II Farm. 2001, 56, 683-687. [CrossRef]

9. Manthey, J.A.; Guthrie, N. Antiproliferative Activities of Citrus Flavonoids against Six Human Cancer Cell Lines. J. Agric. Food Chem. 2002, 50, 5837-5843. [CrossRef]

10. Brglez Mojzer, E.; Knez Hrnčič, M.; Škerget, M.; Knez, Ž.; Bren, U. Polyphenols: Extraction Methods, Antioxidative Action, Bioavailability and Anticarcinogenic Effects. Molecules 2016, 21, 901. [CrossRef]

11. Garg, A.; Garg, S.; Zaneveld, L.J.D.; Singla, A.K. Chemistry and Pharmacology of the Citrus Bioflavonoid Hesperidin. Phytother. Res. 2011, 15, 655-669. [CrossRef] [PubMed]

12. Ma, Y.; Ye, X.; Hao, Y.; Xu, G.; Xu, G.; Liu, D. Ultrasound-assisted extraction of hesperidin from Penggan (Citrus reticulata) peel. Ultrason. Sonochem. 2008, 15, 227-232. [CrossRef] [PubMed]

13. Safdar, M.N.; Kausar, T.; Jabbar, S.; Mumtaz, A.; Ahad, K.; Saddozai, A.A. Extraction and quantification of polyphenols from kinnow (Citrus reticulate L.) peel using ultrasound and maceration techniques. J. Food Drug Anal. 2016, 25, 488-500. [CrossRef] [PubMed]

14. Zainal-Abidin, M.H.; Hayyan, M.; Hayyan, A.; Jayakumar, N.S. New horizons in the extraction of bioactive compounds using deep eutectic solvents: A review. Anal. Chim. Acta 2017, 979, 1-23. [CrossRef] [PubMed]

15. Dai, Y.; van Spronsen, J.; Witkamp, G.J.; Verpoorte, R.; Choi, Y.H. Natural deep eutectic solvents as new potential media for green technology. Anal. Chim. Acta 2013, 766, 61-68. [CrossRef] [PubMed]

16. Bajkacz, S.; Adamek, J. Development of a Method Based on Natural Deep Eutectic Solvents for Extraction of Flavonoids from Food Samples. Food Anal. Methods 2018, 11, 1330-1344. [CrossRef]

17. Liu, Y.; Zhang, H.; Yu, H.; Guo, S.; Chen, D. Deep eutectic solvent as a green solvent for enhanced extraction of narirutin, naringin, hesperidin and neohesperidin from Aurantii Fructus. Phytochem. Anal. 2018, 30, 156-163. [CrossRef]

18. Van den Bruinhorst, A.; Kouris, P.; Timmer, J.M.K.; de Croon, M.H.J.M.; Kroon, M.C. Exploring orange peel treatment with deep eutectic solvents and diluted organic acids. Nat. Prod. Chem Res. 2016, 4, 1-5. [CrossRef]

19. Lota, M.L.; de Rocca Serra, D.; Tomi, F.; Casanova, J. Chemical variability of peel and leaf essential oils of mandarins from Citrus reticulata Blanco. Biochem. Syst. Ecol. 2000, 28, 61-78. [CrossRef]

20. Sun, Y.; Wang, J.; Gu, S.; Liu, Z.; Zhang, Y.; Zhang, X. Simultaneous Determination of Flavonoids in Different Parts of Citrus reticulata 'Chachi' Fruit by High Performance Liquid Chromatography_Photodiode Array Detection. Molecules 2010, 15, 5378-5388. [CrossRef]

21. Budavari, S. (Ed.) The Merck Index: An Encyclopedia of Chemicals, Drugs, and Biologicals, 12th ed.; Merck \& Co, Inc.: Whitehouse Station, NJ, USA, 1996.

22. Bi, W.; Tian, M.; Row, K.H. Evaluation of alcohol based deep eutectic solvent in extraction and determination of flavonoids with response surface methodology optimization. J. Chromatogr. A 2013, 1285, 22-30. [CrossRef] [PubMed]

23. Majumdar, S.; Srirangam, R. Solubility, stability, physicochemical characteristics and in vitro ocular tissue permeability of hesperidin: A natural bioflavonoid. Pharm. Res. 2009, 26, 1217-1225. [CrossRef]

(C) 2019 by the authors. Licensee MDPI, Basel, Switzerland. This article is an open access article distributed under the terms and conditions of the Creative Commons Attribution (CC BY) license (http://creativecommons.org/licenses/by/4.0/). 